\title{
Differences in Anthropometric Characteristics and Body Composition between Rugby Players of National Team of Montenegro and National Team of Bulgaria
}

\author{
Pavle Malovic ${ }^{1}$ \\ 'University of Montenegro, Faculty for Sport and Physical Education, Niksic, Montenegro
}

\begin{abstract}
The aim of this research was to determine the differences among the rugby players of national team of Montenegro and national team of Bulgaria in the morphological characteristics and body composition. A sample of 43 examinees is divided into two sub-samples. The first sub-sample of the examinees consisted of 23 players of rugby national team of Montenegro, while the other sub-sample consisted of 20 players of rugby national team of Bulgaria. Morphological characteristics in the body composition were evaluated by a battery of 10 variables: body height, body weight, triceps skin set, biceps skin set, back skin set, abdominal skin set, thigh skin set, lower leg skin set, body mass index and muscle mass. The standard central and dispersive parameters of all variables are calculated. The significance of the differences between the players of the two national teams in the morphological characteristics and variables for assessing body composition was determined by a t-test for independent samples. It was not found that the rugby players of the two mentioned national teams have statistically significant differences in morphological characteristics and body composition.
\end{abstract}

Key words: Morphological Characteristics, Body Composition, Rugby Montenegro, Rugby Bulgaria

\section{Uvod}

U današnjim uslovima života i rada, sport predstavlja veoma važno područje u kojem čovjek na specifičan način može ispoljiti svoje, prije svega, stvaralačke kretne strukture (Bjelica i Fratrić, 2011). Svaki pojedinac se tokom svog života nalazi u mnoštvu situacija u kojima mora uspješno djelovati sa svojom okolinom, kako fizičkom tako i socijalnom. Potreba pojedinca da upozna svoje sopstvene mogućnosti, za upravo pomenuto djelovanje, ispoljava se na svim uzrastima i kroz svakodnevne životne situacije (Bjelica, 2006). Aktivnost u sportu se odlikuje stalnom težnjom da se prevaziđe već postignuto i upravo je takav odnos neraskidivo vezao sport za takmičenje kao posebnu formu realizacije ljudske ličnosti (Bjelica i Krivokapić, 2010).

Sportske igre karakterišu raznovrsne i mnogobrojne slo- žene dinamičke kineziološke aktivnosti u kojima dominiraju ciklična kretanja (Gardašević, Vasiljević, i Bojanić, 2015; Bjelica, Popović, i Gardašević, 2016a; Bjelica, Popović, i Gardašević, 2016b; Sermaxhaj, Popović, Bjelica, Gardašević, i Arifi, 2017; Gardašević, Bjelica, i Vasiljević, 2017a; Gardašević, Bjelica, i Vasiljević, 2017b) i aciklična kretanja (Gardasevic, 2015;Gardašević i sar.,2015;Gardašević, Bjelica, i Vasiljević, 2016a;Gardašević, Bjelica i Vasiljević, 2016b; Gardašević, Bjelica, Milašinović, i Vasiljević, 2016; Gardaševic i Vasiljević, 2016; Gardašević, Popović, i Bjelica, 2016).

Važan podatak za ovo istraživanje predstavlja 1823. godina i vjerovanje da je čuveni William Webb Ellis, koji je pohađao školu Rugby u gradu Rugby u Engleskoj, u tadašnjoj fudbalskoj igri, koja je bila definisana tako da je lopta mogla da se

Correspondence:

Montenegro P. Malovic

Gport University of Montenegro, Faculty for Sport and Physical Education, Narodne omladine bb, 81400 Niksic, Montenegro E-mail: pavle.malovic93@live.ac.me 
gura bilo rukama, bilo nogama, uzeo loptu u ruke i potrčao prema liniji poentiranja protivničke ekipe. Interesantno je da se igrači protivničke ekipe nijesu zbunili, već su pokušali da ga zaustave obaranjem, što je tadašnja publika podržala i pretpostavlja se da je upravo tako nastao ragbi kao sport. Zvanično je 1863. godine došlo do razdvajanja fudbala od ragbija i formiran je fudbalski savez sa ciljem da se regulišu pravila igre. Trčanje sa loptom je bilo protivzakonito, ali je ragbi nastavio da preferira takvu verziju fudbalske igre.

Kao i svi drugi timski sportovi i ragbi ima fundamentalne komponente koje utiču i regulišu način igranja u ovoj sportskoj igri. Pomenute komponente su tehničke, taktičke, fizičke i psihološke vještine i znanja (Bompa i Claro, 2009). Zahvaljući istraživanjima u sportskoj nauci, ragbi je klasifikovan kao multi-sprint i sport u kojem vlada multi-aktivnost, a razlog tome je što su tokom igre, ragbi igrači izloženi raznim naporima, kao što su sprintevi, razna obaranja, rakovi, molovi, periodi džogiranja, hodanja i stajanja dok se čeka da se izgradi sljedeća akcija (Bompa i Claro, 2009).

Istraživanja antropometrijskih karakteristika i tjelesne kompozicije među sportistima različitih sportova ukazuju na to da sportisti različitih sportova imaju svoja specifična obilježja. Mišićna masa poboljšava sportsko postignuće $\mathrm{u}$ aktivnostima koje zahtijevaju mišićnu snagu i izdržljivost, ali i u onima koje zahtijevaju zavidnu aerobnu sposobnost (Ramadan \& Byrd, 1987; Green, 1992; Rico-Sanz, 1998). U sportskim aktivnostima, tokom treninga i takmičenja, veliku važnost imaju opšte i osnovne antropološke karakteristike (Bjelica, Georgijev, i Muratović, 2012).

Utvrđivanje antropometrijskih karakteristika predstavlja jednu od tri najčešće testiranih dimenzija sportista (Milanović, Jukić, Vuleta, Šimek, i Šentija, 2005). Antropometrijske karakteristike su dio bioloških varijabli koje su vezane za performanse u sportu. U potpunosti je ustanovljeno da je antropometrija važan faktor u selekciji sportista (G. Moreno, L. Moreno, \& Jaramillo, 2011), kao i da otkrije buduće talente u određenim sportskim disciplinama (García, Cañadas, \& Parejo, 2007; Popović, Akpinar, Jakšić, Matić, i Bjelica, 2013). Antropometrijske karakteristike i tjelesna kompozicija sportista su predmet raznih istraživanja u kojima su mnogi istraživači pretpostavili da se od sportista očekuje da posjeduju određene strukturne i funkcionalne karakteristike, koje su posebno pogodne za njihov specifičan sport (S. Singh, K. Singh, \& M. Singh, 2010). Budući da svaki sport ima specifične zahtjeve, svaki sportista bi trebalo da ima specifične antropometrijske karakteristike i tjelesnu kompoziciju koji odgovara njegovoj ili njenoj sportskoj disciplini (Norton, Olds, Olive, \& Craig, 2004). Brojna istrazivanja su sproveli istraživači sa Fakulteta za sport i fizičko vaspitanje iz Nikšića u kojima su vršili procjenu morfoloških karakteristika i sastava tijela igrača najboljih fudbalskih klubova u Bosni i Hercegovini (Corluka et al., 2018), kao i u Crnoj Gori (Corluka \& Vasiljevic, 2018; Gardasevic, Bjelica, Popovic, Vasiljevic, \& Milosevic, 2018; Bjelica, Gardasevic, \& Vasiljevic, 2018). Za ovo istrazivanje konkretno su dvije reprezentacije bile u fokusu, a to su ragbi reprezentacija Crne Gore i reprezentacija Bugarske koje su se takmičile u okviru Evropskog kupa nacija. Interesantno za ovo istraživanje je bilo to što je utakmica završena 57-0 u korist reprezentacije Bugarske, pa upravo se željelo doći do rezultata makar u jednom segmentu onih činilaca koji su mogli uticati na ishod ove utakmice, a to su upravo antropometrijske karakteristike i tjelesna kompozicija.
Cilj ovog istraživanja je bio da se evidentiraju eventualne razlike u pojedinim, izmjerenim varijablama koje procjenjuju antropometrijske karakteristike i tjelesnu kompoziciju reprezentativaca nacionalnih timova Crne Gore i Bugarske.

\section{Metod}

Podaci dobijeni u istraživanju antropometrijskih karakteristika i tjelesne kompozicije, kontrolisani su i pripremljeni za obradu u skladu sa postavljenim ciljem. Baze podataka su sređene po praćenim obilježjima i pripremljene za planiranu statističku obradu. Rezultati dobijeni statističkom obradom prikazani su u tabelama i analizirani po pripadajućim logičkim cjelinama. U cjelini posmatrano, prikaz rezultata istraživanja, kroz postupnost u obrazlaganju pojedinačnih veza, omogućava sagledavanje razlika u posmatranim antropometrijskih karakteristika i tjelesnoj kompoziciji, u skladu sa ciljem istraživanja, odnosno doprinosi jasnom određenju prema očekivanoj primjeni dobijenih rezultata $u$ praksi. U pogledu vremenske određenosti istraživanje je transverzalnog karaktera, a sastoji se u jednokratnom mjerenju odgovarajućih antropometrijskih karakteristika i tjelesne kompozicije igrača ragbi reprezentacije Crne Gore i reprezentacije Bugarske.

\section{Uzorak ispitanika}

$\mathrm{U}$ ovom istraživanju uzorak ispitanika činili su igrači seniorske ragbi reprezentacije Crne Gore i igrači seniorske ragbi reprezentacije Bugarske. Ukupan broj ispitanika je 43. Svi ispitanici su podijeljeni na dva subuzora. Prvi subuzorak su činili 23 igača seniorske ragbi reprezentacije Crne Gore, dok su drugi subuzorak činili 20 igrača seniorske ragbi reprezentacije Bugarske. U oba subuzorka pol igrača je bio ravnopravno zastupljen, odnosno pol je muški kod svih ispitanika.

\section{Uzorak mjera}

Antropometrijsko istraživanje je sprovedeno uz poštovanje osnovnih pravila i principa vezanih za izbor mjernih instrumenata i tehnike mjerenja koji su standardizovani, prema upustvima Internacionalnog Biološkog Programa. Za potrebe ovog istraživanja je izmjereno osam antropometrijskih mjera: visina tijela (ATV), težina tijela (ATM), kožni nabor tricepsa (ANT), kožni nabor bicepsa (ANB), kožni nabor leđa (ANL), kožni nabor trbuha (ANT), kožni nabor potkoljenice (ANP), kožni nabor natkoljenice (ANN) i dvije mjere za procjenu tjelesne konstitucije: indeks tjelesne mase (BMI), mišićna masa (AMM).

$\mathrm{Za}$ mjerenje antropometrijskih karakteristika korišćeni su antropometar i kaliper. Za procjenu tjelesne kompozicije korišćena je tanita vaga, model BC-418MA, pomoću koje su se dobili egzaktni podaci o indeksu tjelesne mase i vrijednosti mišićne mase za svakog igrača posebno. Ova vaga funkcioniše na principu indirektnog mjerenja tjelesne kompozicije, tokom kojeg se bezbjedan električni signal šalje kroz tijelo preko elektroda koje su smještene u samostalnu jedinicu. Tanita vaga ima mogućnost podešavanja atletskog moda koji omogućava sportistima detaljno praćenje tjelesne težine, zdravstvenog stanja i kondicije, sa svim relevantim parametrima.

\section{Metoda obrade podataka}

Podaci dobijeni istraživanjem obrađeni su postupcima deskriptivne i komparativne statističke procedure. Za svaku varijablu su obrađeni centralni i disperzioni parametri kao i mjere asimetrije i spljoštenosti.Razlike u antropometrijskim karateristikama i tjelesnoj kompoziciji ragbista ove dvije reprezen- 
tacije utvrđene su primjenom diskriminativne parametrijske procedure, t-testom za male nezavisne uzorke, sa statističkom značajnošću od $\mathrm{p}<0.05$.

\section{Rezultati}

U Tabelama 1. i 2. prikazani su osnovni deskriptivni statistički parametri antropometrijskih varijabli i tjelesne kompozicije ragbista ove dvije reprezentacije, đe su izračunate vrijed- nosti mjera centralne i disperzione tendencije i to: aritmetička sredina (Mean), raspon (Range), standardna devijacija (Std. Dev.), varijansa (Variance), minimalne (Min) i maksimalne (Max) vrijednosti, koeficijenti zakrivljenosti (Skewness) i izduženosti (Kurtosis).

Prvo su analizirani centralni i disperzioni parametri varijabli za procjenu antropometrijskih karakteristika i tjelesne kompozicije ragbista nacionalnog tima Crne Gore (Tabela 1).

Tabela 1. Centralni i disperzioni parametri varijabli za procjenu antropometrijskih karakteristika i tjelesne kompozicije ragbi igrača reprezentacije Crne Gore ( $\mathrm{N}=23)$

\begin{tabular}{|c|c|c|c|c|c|c|c|c|c|c|}
\hline & \multirow{2}{*}{ Range } & \multirow{2}{*}{ Min } & \multirow{2}{*}{ Max } & \multirow{2}{*}{ Mean } & \multirow{2}{*}{ Std. D. } & \multirow{2}{*}{ Variance } & \multicolumn{2}{|c|}{ Skewness } & \multicolumn{2}{|c|}{ Kurtosis } \\
\hline & & & & & & & Stat. & Std.E. & Stat. & Std.E. \\
\hline ATV & 37.00 & 163.00 & 200.00 & 182.1522 & 10.10350 & 102.081 & -.221 & .481 & -.467 & .935 \\
\hline ATM & 55.30 & 64.10 & 119.40 & 96.3913 & 13.24005 & 175.299 & -.297 & .481 & .186 & .935 \\
\hline ANT & 13.40 & 4.40 & 17.80 & 9.7739 & 3.33374 & 11.114 & .588 & .481 & .112 & .935 \\
\hline ANB & 5.40 & 3.20 & 8.60 & 5.6000 & 1.31426 & 1.727 & .246 & .481 & .243 & .935 \\
\hline ANL & 23.20 & 9.60 & 32.80 & 19.3522 & 6.15260 & 37.854 & .204 & .481 & -.375 & .935 \\
\hline ANS & 33.80 & 6.40 & 40.20 & 18.9826 & 9.30511 & 86.585 & .786 & .481 & -.052 & .935 \\
\hline ANP & 18.60 & 4.80 & 23.40 & 15.2739 & 4.42865 & 19.613 & -.509 & .481 & .282 & .935 \\
\hline ANN & 24.40 & 7.00 & 31.40 & 16.2261 & 4.80655 & 23.103 & 1.309 & .481 & 4.103 & .935 \\
\hline BMI & 13.30 & 22.40 & 35.70 & 29.0478 & 2.81584 & 7.929 & -.162 & .481 & 1.040 & .935 \\
\hline AMM & 12.00 & 41.00 & 53.00 & 46.4783 & 2.62626 & 6.897 & .101 & .481 & .744 & .935 \\
\hline
\end{tabular}

Legenda: visina tijela (ATV), težina tijela (ATM), kožni nabor tricepsa (ANT), kožni nabor bicepsa (ANB), kožni nabor leđa (ANL), kožni nabor trbuha (ANS) kožni nabor potkoljenice (ANP), kožni nabor natkoljenice (ANN), indeks tjelesne mase (BMI), mišićna masa (AMM).

Na osnovu centralnih i disperzionih parametara, vrijednosti skjunisa i kurtozisa može se konstatovati da su svi rezultati u granicama normalne raspodjele. Može se primijetiti po vrijednostima skjunisa da postoji blaga asimetrija u varijabli kožni nabor natkoljenice (ANN), ali ne i statistički značajno, što bi značilo da u statističkoj seriji ima više rezultata manjih od aritmetičke sredine kada je u pitanju potkožno masno tkivo na natkoljenici. Po vrijednostima kurtozisa može se konstatovati da kod varijable indeksa tjelesne mase (BMI) postoji blago odstupanje rezultata od normalne raspodjele i oblikuje se lepto- kurtični oblik Gausove krive, ali nije statistički značajno, dok se kod varijable kožni nabor natkoljenice (ANN) zapaža statistički značajno odstupanje u kojem su rezultati koncentrisani bliže centralnim vrijednostima, odnosno izrazito su homogeni i čine leptokurtičnu krivu. Na osnovu ovih statističkih parametara generalno se može konstatovati da su njihovi rezultati testiranih varijabli u normalnom rasporedu i da preovladavaju bolji rezultati od aritmetičke sredine, ali ne i statistički značajni, jer se očekuje da ne bude veliki raspon u rezultatima kod osoba koje su fizički aktivne duži niz godina.

Tabela 2. Centralni i disperzioni parametri varijabli za procjenu antropometrijskih karakteristika i tjelesne kompozicije ragbi igrača reprezentacije Bugarske $(\mathrm{N}=20)$

\begin{tabular}{|c|c|c|c|c|c|c|c|c|c|c|}
\hline & \multirow{2}{*}{ Range } & \multirow{2}{*}{ Min } & \multirow{2}{*}{ Max } & \multirow{2}{*}{ Mean } & \multirow{2}{*}{ Std. D. } & \multirow{2}{*}{ Variance } & \multicolumn{2}{|c|}{ Skewness } & \multicolumn{2}{|c|}{ Kurtosis } \\
\hline & & & & & & & Stat. & Std. E. & Stat. & Std. E. \\
\hline ATV & 24.00 & 168.0 & 192.00 & 179.8500 & 6.97005 & 48.582 & .010 & .512 & -.854 & .992 \\
\hline ATM & 52.90 & 75.70 & 128.60 & 99.7450 & 14.36679 & 206.405 & .292 & .512 & -.727 & .992 \\
\hline ANT & 13.40 & 4.60 & 18.00 & 10.0200 & 3.84428 & 14.779 & .613 & .512 & -.105 & .992 \\
\hline ANB & 7.00 & 3.20 & 10.20 & 5.6000 & 2.03754 & 4.152 & 1.039 & .512 & .328 & .992 \\
\hline ANL & 36.00 & 8.20 & 44.20 & 21.0500 & 9.70228 & 94.134 & 1.199 & .512 & 1.111 & .992 \\
\hline ANS & 37.40 & 7.00 & 44.40 & 22.1300 & 9.85095 & 97.041 & .554 & .512 & -.110 & .992 \\
\hline ANP & 20.40 & 5.40 & 25.80 & 15.3600 & 6.53657 & 42.727 & .216 & .512 & -1.189 & .992 \\
\hline ANN & 24.60 & 7.60 & 32.20 & 19.2000 & 7.46952 & 55.794 & .220 & .512 & -1.117 & .992 \\
\hline BMI & 15.50 & 23.90 & 39.40 & 30.8150 & 4.00214 & 16.017 & .614 & .512 & -.080 & .992 \\
\hline AMM & 11.00 & 41.00 & 52.00 & 47.5000 & 2.98240 & 8.895 & -.503 & .512 & -.118 & .992 \\
\hline
\end{tabular}

$\mathrm{Na}$ osnovu centralnih i disperzionih parametara, vrijednosti skjunisa i kurtozisa može se konstatovati da su svi rezultati u granicama normalne raspodjele. Takođe, po vrijednostima skjunisa, zapaža se da u sljedećim varijablama: kožni nabor bicepsa (ANB), kožni nabor leđa (ANL) postoji blaga asimetrija, ali ne i statistički značajna u stranu boljih rezultata iako je predznak pozitivan, a pretpostavlja se da je u timu više igrača koji pokrivaju pozicije koje zahtijevaju manji procenat masnog tkiva, od onih kojima tjelesna masa igra presudnu ulogu u timu, a samim tim tjelesna masa je pretežno praćena i visokim procentom masne komponente. Po vrijednostima kurtozisa se vidi kod sljedećih varijabli: kožni nabor leđa (ANL), kožni nabor potkoljenice (ANP) i kožni nabor natkoljenice (ANN) blago odstupanje rezultata od 
normalne raspodjele, koje nije statistički značajno. Kod varijable kožnog nabora na leđima (ANL) zapaža se situacija na osnovu koje se može konstatovati da su rezultati raspoređeni oko aritmetičke sredine i obrazuju leptokurtičnu krivu, a kod preostale dvije varijable se evidentira blaga platikurtičnost, ali ne i statistički značajna. Iz ovoga se može izvesti konstatacija da postoje različiti rezultati u ovim varijablama koji nijesu raspoređeni oko aritmetičke sredine, a vjerovatno zbog toga što u ragbiju postoje izrazito različite konstitucije igrača u odnosu na poziciju koju pokrivaju, a samim tim i procenat masnog tkiva varira u određenim vrijednostima. $\mathrm{Na}$ osnovu ovih statističkih parametara generalno se može konstatovati da se radi o osobama koje su duži vremenski period u trenažnom procesu i profesionalno se bave ragbijem, a samim tim i njihovi rezultati testiranih varijabli su u normalnom rasporedu i da preovladavaju bolji rezultati od aritmetičke sredine, ali ne i statistički značajni, jer se očekuje da ne bude veliki raspon u rezultatima kod osoba koje se, kako je navedeno, profesionalono bave ragbijem duži vremenski period. Da bi se utvrdilo da li ima statistički značajne razlike $\mathrm{u}$ analiziranim varijablama kod ragbi igrača ova dva nacionalna tima, primijenjena je statistička procedura t-test (Tabela 3.).

Tabela 3. Vrijednosti t-testa između aritmetičkih sredina varijabli za procjenu antropometrijskih karakteristika i tjelesne kompozicije ragbi igrača reprezentacije Crne Gore $(\mathrm{N}=23)$ i reprezentacije Bugarske $(\mathrm{N}=20)$

\begin{tabular}{|c|c|c|c|c|c|c|c|}
\hline & Ekipa & Mean & Std. D. & Std. E. M. & t-test & Sig. & Mean difference \\
\hline \multirow{2}{*}{ ATV } & CG & 182.1522 & 10.1035 & 2.10673 & \multirow{2}{*}{.856} & \multirow{2}{*}{.397} & \multirow{2}{*}{2.30217} \\
\hline & BUG & 179.8500 & 6.9700 & 1.55855 & & & \\
\hline \multirow{2}{*}{ ATM } & CG & 96.3913 & 13.2400 & 2.76074 & \multirow{2}{*}{-.796} & \multirow{2}{*}{.430} & \multirow{2}{*}{-3.35370} \\
\hline & BUG & 99.7450 & 14.3667 & 3.21251 & & & \\
\hline \multirow{2}{*}{ ANT } & CG & 9.7739 & 3.3337 & 69513 & \multirow{2}{*}{-.225} & \multirow{2}{*}{.823} & \multirow{2}{*}{-.24609} \\
\hline & BUG & 10.0200 & 3.8442 & .85961 & & & \\
\hline \multirow{2}{*}{ ANB } & CG & 5.6000 & 1.3142 & .27404 & \multirow{2}{*}{.000} & \multirow{2}{*}{1.000} & \multirow{2}{*}{.00000} \\
\hline & BUG & 5.6000 & 2.0375 & .45561 & & & \\
\hline \multirow{2}{*}{ ANL } & CG & 19.3522 & 6.1526 & 1.28290 & \multirow{2}{*}{-.694} & \multirow{2}{*}{.491} & \multirow{2}{*}{-1.69783} \\
\hline & BUG & 21.0500 & 9.7022 & 2.16950 & & & \\
\hline \multirow{2}{*}{ ANS } & CG & 18.9826 & 9.3051 & 1.94025 & \multirow{2}{*}{-1.077} & \multirow{2}{*}{.288} & \multirow{2}{*}{-3.14739} \\
\hline & BUG & 22.1300 & 9.8509 & 2.20274 & & & \\
\hline \multirow{2}{*}{ ANP } & CG & 15.2739 & 4.4286 & .92344 & \multirow{2}{*}{-.051} & \multirow{2}{*}{.959} & \multirow{2}{*}{-.08609} \\
\hline & BUG & 15.3600 & 6.5365 & 1.46162 & & & \\
\hline \multirow{2}{*}{ ANN } & CG & 16.2261 & 4.8065 & 1.00224 & \multirow{2}{*}{-1.573} & \multirow{2}{*}{.123} & \multirow{2}{*}{-2.97391} \\
\hline & BUG & 19.2000 & 7.4695 & 1.67023 & & & \\
\hline \multirow{2}{*}{$\mathrm{BMI}$} & CG & 29.0478 & 2.8158 & .58714 & \multirow{2}{*}{-1.691} & \multirow{2}{*}{.098} & -176717 \\
\hline & BUG & 30.8150 & 4.0021 & .89491 & & & אום \\
\hline AMM & CG & 46.4783 & 2.62626 & .54761 & -1.195 & .239 & -1.02174 \\
\hline
\end{tabular}

Na osnovu dobijenih vrijednosti rezultata t-testa, može se primijetiti da ne postoje statistički značajne razlike između ove dvije ekipe, na nivou značajnosti $\mathrm{p}<0.05$. Uvidom $\mathrm{u}$ numeričke vrijednosti testiranih varijabli, može se konstatovati da igrači ragbi reprezentacije Bugarske imaju neznatno veće brojčane vrijednosti u većini testiranih varijabli, međutim ne i statistički značajno, dok blagu prednost u numeričkim vrijednostima ragbi igrači Crne Gore imaju u varijabli tjelesna visina (ATV), ali takođe ne i statistički značajno.

\section{Diskusija}

Cilj ovog istraživanja je bio da se utvrdi da li postoji statistički značajna razlika u antropometrijskim karakteristikama i kompoziciji tijela između igrača ragbi reprezentacije Crne Gore i igrača ragbi reprezentacije Bugarske. Uzorak od ukupno 43 ispitanika je podijeljen na dva subuzorka. Prvi subuzorak su činili 23 igrača ragbi reprezentacije Crne Gore, dok su drugi subuzorak činili 20 igrača ragbi reprezentacije Bugarske. Rezultati su dobijeni korišćenjem baterije od 10 testova iz prostora antropometrijskih karakteristika i tjelesne kompozicije. Uvidom u osnovne deskriptivne statističke parametre može se zaključiti da se radi o osobama koje su duži vremenski period u trenažnom procesu i da njihovi rezultati odgovaraju datoj disciplini. Vidi se da su igrači obje reprezentacije približnih srednjih vrijednosti analiziranih varijabli, što i ne čudi jer se radi o dvije reprezentacije koje se takmiče u istoj diviziji. Rezultati t-testa su pokazali da ne postoje statistički značajne razlike u testiranim varijablama, iako u većini testiranih varijabli veće numeričke vrijednosti imaju igrači reprezentacije Bugarske. Naime, veće vrijednosti imaju u onim segmentima koji se odnose na tjelesnu masu (ATM), indeks tjelesne mase (BMI), vrijednosti mišićne mase (AMM), kao i vrijednostima kožnih nabora, osim u slučaju kožnog nabora bicepsa (ANB) đe su rezultati u potpunosti identični, dok igrači reprezentacije Crne Gore imaju veće vrijednosti u varijabli tjelesne visine (ATV). Dalje, na osnovu iznesenog zaključka da se kod igrača ragbi reprezentacije Bugarske uočavaju veće vrijednosti u segmentu mišićne mase (AMM), moglo bi se generalno tumačiti da ovo predstavlja bolje rezultate i faktor koji pozitivno utiče na uspješnost u ovom sportu. Što se tiče kožnih nabora i indeksa tjelesne mase, igrači reprezentacije Crne Gore imaju rezultate sa manjim vrijednostima, što bi se moglo okarakterisati kao bolji rezultat u ovom sportu u odnosu na igrače nacionalnog tima Bugarske, jer rezultati kožnih nabora indirektno daju podatke o masnoj komponenti, a masna komponenta nikako ne može biti poželjan faktor u ragbiju. Što se tiče tjelesne mase (ATM) i tjelesne visine (ATV), može se konstatovati da su usko povezane sa pozicijom u timu, jer upravo neke pozicije, kao što su igrači koji čine skram ragbi ekipe, zahtijevaju veću tjelesnu masu, kao i visinu od ostalih igrača u timu. Stoga se 
ne može precizno reći koja od ove dvije reprezentacije ima povoljnije rezultate u ovim varijablama, pa samim tim, da bi se o ovome govorilo egzaktnije moralo bi i samo istraživanje biti mnogo opširnije i temeljnije.

\section{Acknowledgements}

There are no acknowledgements.

\section{Conflict of Interest}

The authors declare that there are no conflicts of interest.

Received: 22 August 2018| Accepted: 29 September 2018| Published: 29 October 2018

\section{References}

Bjelica, D. (2006). Sportski trening. Nikšić: Filozofski fakultet Univerziteta Crne Gore.

Bjelica, D. i Krivokapić, D. (2010). Teorijske osnove fizičke kulture. Nikšić Fakultet za sport i fizičko vaspitanje Univerziteta Crne Gore.

Bjelica, D., Popović, S. i Gardašević, J. (2016a). Modeli fizičke pripreme vrhunskih sportaša i doziranje opterećenja. Zbornik radova 14.godišn je međunarodne konferencije „Kondicijska priprema sportaša” (185-189), Zagreb: Udruga kondicijskih trenera Hrvatske.

Bjelica, D., Popović, S. i Gardašević, J. (2016b). Opći principi planiranja programiranja fizičkih priprema sportaša. Zbornik radova 14.godišnje međunarodne konferencije "Kondicijska priprema sportaša" (190-192), Zagreb: Udruga kondicijskih trenera Hrvatske.

Bjelica, D., Georgiev, G. i Muratović, A. (2012). Basic motor abilities of young handball players from Montenegro. Sport Science, 5(1), 71-6.

Bjelica, D. i Fratrić, F. (2011). Sportski trening: teorija, metodika i dijagnostika. Nikšić: Fakultet za sport i fizičko vaspitanje.

Bjelica, D., Gardasevic, J.\& Vasiljevic, I. (2018). Differences in the morphological characteristics and body composition of football players FC Sutjeska and FC Mladost in Montenegro. Journal of Anthropology of Sport and Physical Education, 2(2), 31-5. doi: 10.26773/jaspe.180406

Bompa, T. \& Claro, F. (2009). Periodization in rugby. United Kingdom: Mayer \& Mayer Sport.

Corluka, M., Bjelica, D., Vasiljevic, I., Bubanja, M., Georgiev, G.\& Zeljko, I. (2018). Differences in the morphological characteristics and body composition of football players of HSC Zrinjski Mostar and FC Siroki Brijeg in Bosnia and Herzegovina. Sport Mont, 16(2), 77-81. doi: 10.26773/ smj.180614.

Corluka, M. \& Vasiljevic, I. (2018). Differences in the morphological characteristics and body composition of football players in Montenegro. Journal of Anthropology of Sport and Physical Education, 2(1), 3-7. doi: 10.26773/ jaspe.180101

García, J., Cañadas, M. \& Parejo, I. (2007 Una revisión sobre la detección y selección del talento en balonmano. E-Balonmano.com: Revista Digital Deportiva, 3(3), 39-46.

Gardasevic, J. (2015). The effects of the training in the preparation period on the agility transformation with cadet level football players. Book of Abstracts of the 12th International Scientific Conference on Transformation Process in Sport "Sport Performance" (76-77), Podgorica: Montenegrin Sports Academy.

Gardašević, J., Vasiljević, I., Bojanić, D., Muratović, A., Ljubojević, M., Milašinović, R. i Bubanja, M. (2015). Sixweek Preparation Period and its Effects on Transformation Movement Speed with Football Players Under 16. Book of Abstracts, International Scientific Conference "Effects of Physical Activity Application to Anthropological Status with Children, Youth and Adults" (148), Belgrade:University of Belgrade: Faculty of Sport and Physical Education.

Gardašević, J., Bjelica, D. i Vasiljević, I. (2016a). Six-Week Preparation Period and its Effects on Transformation Movement Speed with Football Players Under 16. Sport Mont, 14(1), 13-16.

Gardašević, J., Bjelica, D. i Vasiljević, I. (2016b). The Effects of the Training in the Preparation Period on the Repetitive Strength Transformation With Cadet Level Football Players. Book of Abstracts of the 13th International Scientific Conference on Transformation Processes in Sport "Sport Performance" (43), Podgorica: Montenegrin Sports Academy.

Gardašević, J., Bjelica, D. i Vasiljević, I. (2017a). The strength of kicking the ball after preparation period with U15 football players. Book of Abstracts of the 14th International Scientific Conference on Transformation Processes in Sport „Sport Performance” (65-66), Podgorica: Montenegrin Sports Academy.

Gardasevic, J., Bjelica, D. i Vasiljevic, I. (2017b). The Strength of Kicking the Ball after Preparation Period with U15 Football Players. Sport Mont, 15(2), 39-42.

Gardašević, J., Bjelica, D., Milašinović, R. i Vasiljević, I. (2016). The Effects of the Training in the Preparation Period on the Repetitive Strength Transformation with Cadet Level Football Players. Sport Mont, 14(2), 31-3.

Gardaševic, J.i Vasiljević, I. (2016). Effects of Preparation Period on Endurance in U16 Football Players. Book of Abstracts of the 4TH International Scientific Conference "Exercise and Quality of Life" (108), Novi Sad: University of Novi Sad, Faculty of Sport and Physical Education.

Gardašević, J., Vasiljević, I., \& Bojanić, D. (2015). Six-week preparation period and its effects on coordination transformation with football players under 16. Book of Abstracts 11th InternationalScientific Conference Management, Sport, Olympism (36), Beograd: Fakultet za menadžment u sportu, Alfa univerzitet.

Gardašević, J., Popović, S. i Bjelica, D. (2016). After preparation period ball shooting accuracy at players U15. In Abstract Book of the 8th Conference for Youth Sport (88), Ljubljana: University of Ljubljana, Faculty of Sport.

Gardasevic, J., Bjelica, D., Popovic, S., Vasiljevic, I.\& Milosevic, Z. (2018). Differences in the morphological characteristics and body composition of football players FC Buducnost and FC Mladost in Montenegro. Journal of Anthropology of Sport and Physical Education, 2(1), 51-5. doi: 10.26773/ jaspe. 180109

Green, S. (1992). Anthropometric and physiological characteristics of south Australian soccer players. Australian Journal of Science and Medicine in Sport, 24, 3-7.

Ramadan, J. \& Byrd, R. (1987). Physical characteristics of elite soccer players. Journal of Sports Medicine and Physical Fitness, 27, 424-28.

Milanović, D., Jukić, I., Vuleta, D., Šimek, S. i Šentija D. (2005). Measurement and evaluation of fitness characteristics of Croatian handball players. Zbornik radova Sports Kinetics' 2005 "Scientific Fundaments of Human and Sport Practice", (444-48).

Moreno, G. A., Moreno, L. E. A. \& Jaramillo, P. C. A. (2011). Characterization of karate athletes and college basketball: body composition and anthropometry stability. Rev. Edu-Fisica., 3(8), 1-20.

Norton, K., Olds, T., Olive, S. \& Craig, N. (2004). Anthropometry and sports performance. In: Norton, K. \& Olds, T. (Eds.). Anthropometrica. Sydney, University of New South Wales Press. 287-364.

Popović, S., Akpinar, S., Jaksić, D., Matić, R. \& Bjelica, D. (2013). Comparative Study of Anthropometric Measurement and Body Composition between Elite Soccer and Basketball Players .Int. J. Morphol., 31(2), 461-7.

Sermaxhaj, S., Popović, S., Bjelica, D., Gardašević, J. i Arifi, F. (2017). Effect of recuperation with static stretching in isokinetic force of young football players. Journal of Physical Education and Sport, 17(3), 1948-53. doi: 10.7752/jpes.2017.03191.

Singh, S., Singh, K. \& Singh, M. (2010). Anthropometric measurements, body composition and somatotyping of high jumpers. Braz. J. Biomotricity, 4(4), 266-71.

Rico-Sanz, J. (1998). Body composition and nutritional assessments in soccer. International Journal of Sport Nutrition, 8, 113-23. 